Check for updates

Cite this: DOI: 10.1039/d0qm00407c

\title{
Synthesis and excited state processes of arrays containing amine-rich carbon dots and unsymmetrical rylene diimides $\uparrow$
}

\author{
Luka Đorđević, (D) $\ddagger \S^{\star^{a}}$ Philipp Haines, ${ }^{b}$ Michele Cacioppo, ${ }^{a}$ Francesca Arcudi, $\S^{a}$ \\ Tobias Scharl, ${ }^{b}$ Alejandro Cadranel, (D) bed Dirk M. Guldi (iD *b and \\ Maurizio Prato iD *aef
}

\begin{abstract}
Combining carbon dots (CDs) with $\pi$-extended chromophores is an attractive way to study the electronic and energy processes of the former as a key step to many applications, including photosensing, photocatalysis, or photosensitization. CDs, in conjugation with chromophores, can have value in preparing donor-acceptor hybrids, and can also be used as scaffolds to support electronic communication between dyes. In this work, we conjugate two different rylene diimides, naphthalene and perylene diimides (NDI and PDI, respectively), with amorphous nitrogen-doped carbon dots. We take advantage of the imidization reaction between the amine-rich surface of the carbon dots and the monimide monoanhydride precursors of NDIs and PDIs, under microwave assisted conditions. The resulting (nano)hybrids were characterized also by spectroscopic methods. In particular, time-resolved spectroscopy for the multichromophoric array, consisting of CDs and both rylene diimides, allowed us to elucidate the complex inter-chromophoric interactions taking place in the excited state.
\end{abstract}

Received 17th June 2020

Accepted 14th August 2020

DOI: $10.1039 / \mathrm{dOqm00407c}$

rsc.li/frontiers-materials

\section{Introduction}

The organization of chromophores is of crucial importance for a wide variety of technological applications. Particularly in the field of materials science, numerous approaches have

\footnotetext{
${ }^{a}$ Department of Chemical and Pharmaceutical Sciences, University of Trieste, and INSTM UdR Trieste, Via Licio Giorgieri 1, 34127 Trieste, Italy.

E-mail:dordevic.luka@gmail.com, prato@units.it

${ }^{b}$ Department of Chemistry and Pharmacy, Interdisciplinary Center for Molecular Materials, Friedrich-Alexander Universität Erlangen-Nürnberg Egerlandstraße 3, 91058 Erlangen, Germany. E-mail: dirk.guldi@fau.de

${ }^{c}$ Universidad de Buenos Aires, Facultad de Ciencias Exactas y Naturales, Departamento de Química Inorgánica, Analítica y Química Física, Pabellón 2, Ciudad Universitaria, C1428EHA, Buenos Aires, Argentina

${ }^{d}$ CONICET - Universidad de Buenos Aires. Instituto de Quimica Física de Materiales, Medio Ambiente y Energía (INQUIMAE), Pabellón 2, Ciudad Universitaria, C1428EHA, Buenos Aires, Argentina

${ }^{e}$ Center for Cooperative Research in Biomaterials (CIC biomaGUNE), Basque Research and Technology Alliance (BRTA), Paseo de Miramon 182, 20014, Donostia San Sebastián, Spain

${ }^{f}$ Basque Foundation for Science, Ikerbasque, Bilbao 48013, Spain

$\dagger$ Electronic supplementary information (ESI) available: Instruments and methods, syntheses, characterizations, steady- and time-resolved spectroscopy. See DOI: $10.1039 / \mathrm{d} 0 \mathrm{qm} 00407 \mathrm{c}$

\# Present address: Simpson Querrey Institute, Northwestern University, $303 \mathrm{E}$. Superior, Chicago, Illinois 60611, USA.

$\S$ Present address: Department of Chemistry, Northwestern University, 2145 Sheridan Road, Evanston, Illinois 60208, USA.
}

been developed to arrange chromophores into functional architectures. ${ }^{1}$ Inspired by natural light-harvesting complexes, in which the precise positioning of chromophores is accomplished thanks to a protein scaffold, ${ }^{2}$ various methods and artificial scaffolds have been explored to mimic the biomolecular units. Several supramolecular and covalent systems that have been developed are based on rigid helical polymers, ${ }^{3}$ nucleic acids, ${ }^{4}$ micelles, ${ }^{5}$ and carbon nanomaterials, ${ }^{6}$ to name a few.

Among the various carbon nanomaterials, small $(<10 \mathrm{~nm})$ carbon nanoparticles called carbon dots (CDs) have emerged due to their peculiar properties, mainly the photophysical ones. ${ }^{7}$ Coupled with ready availability, water solubility and low toxicity of CDs, all of the above reasons suggest why this class of nanomaterial has recently attracted attention. Combination of CDs with $\pi$-extended chromophores and other nanomaterials has been an interesting way to study the electronic and energy processes of the former, as a key step to many applications, including photocatalysis, photosensing, or photosensitization. ${ }^{8}$ Our groups and others have coupled, through supramolecular and covalent chemistry, CDs with chromophoric systems that include porphyrins, ${ }^{9}$ perylene diimides, ${ }^{10} \pi$-extended tetrathiafulvalenes, ${ }^{11}$ pyrenes $^{12}$ and other nanomaterials. ${ }^{13}$

We have placed particular attention on amorphous nitrogendoped CDs ( $a$-N-CDs or carbon nanodots, NCNDs). ${ }^{7 b}$ These small and monodisperse $(2.5 \pm 0.8 \mathrm{~nm})$ CDs can be prepared by fast hydrothermal microwave-assisted heating, using a 
two-component approach, ${ }^{7 b}$ resulting in nanoparticles with an amine-rich surface. These amino groups have been exploited for carbodiimide-mediated amide couplings with chromophores bearing carboxylic groups, including $\mathrm{Ru}(\mathrm{bpy})_{3}{ }^{2+},{ }^{14}$ porphyrins ${ }^{15}$ and phthalocyanines. ${ }^{16}$ In the first example, the conjugation resulted in a high electroluminescent emission, with the carbon nanodots acting as co-reactant to the ruthenium dye emitter. ${ }^{14}$ In the case of the free-base meso-tetrakisarylporphyrin and NCNDs hybrid, it was observed that visible light excitation is followed by a charge separation (one-electron reduced NCNDs and one-electron oxidized porphyrin) and recombination. ${ }^{15}$ Finally, even in cases where carbon nanodots and chromophores do not seem to interact, the former can support the electronic communication between a pair of chromophores. This was observed very recently when, upon light irradiation, a pair of zinc phthalocyanines present on the NCND surface underwent symmetry-breaking charge transfer/separation and recombination dynamics.

Now, we report the preparation of covalent conjugates between carbon dots and naphthalene diimides (NDIs) and perylene diimides (PDIs), as depicted in Fig. 1. We show that a direct (microwave-assisted) imidization reaction between the amino groups on the surface of CDs and the rylene monoanhydride monoimide precursors is a convenient and efficient strategy for conjugation. The rylene dyes were chosen because their widespread use as colorants, their great chemical, thermal, and photo stabilities, in addition to high extinction coefficients. ${ }^{17}$ Furthermore, rylene diimides have been widely used not only as n-type organic semiconductors, ${ }^{18}$ but were also employed as multichromophoric nanoemitters or as light harvesters, used to study

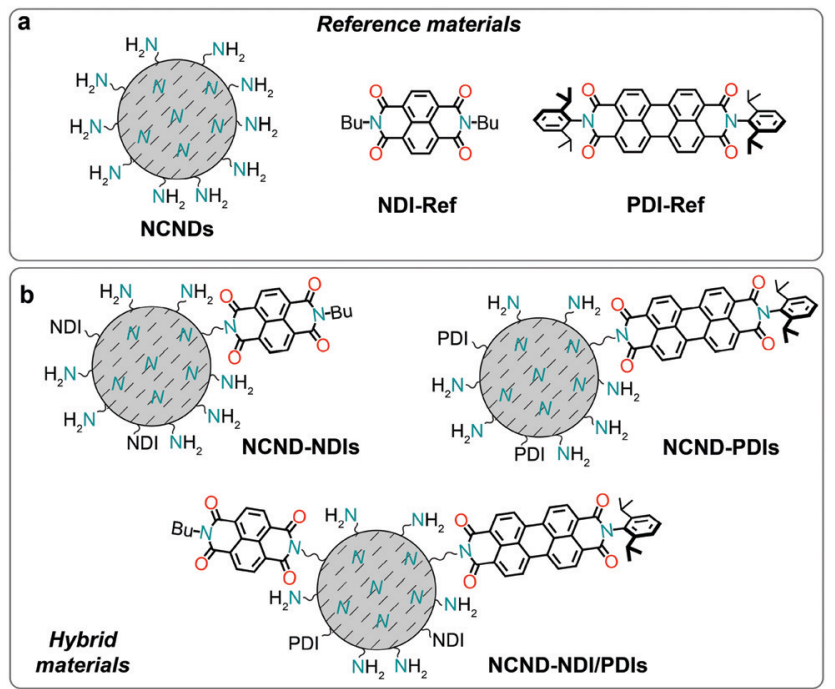

Fig. 1 Schematic representation of the materials used in this work (a) Reference materials, which include amorphous $\mathrm{N}$-doped carbon dots (a-N-CDs, or NCNDs), naphthalene diimide and perylene diimide reference compounds, NDI-Ref and PDI-Ref, respectively. (b) Hybrid materials that include carbon dots with unsymmetrical naphthalene diimide (NCNDNDIs), carbon dots with unsymmetrical perylene diimide (NCND-PDIs) and carbon dots with unsymmetrical naphthalene diimide and perylene diimide (NCND-NDI/PDIs). electron transfer and energy cascades processes in multichromophore arrangements, ${ }^{19}$ as well as in photoredox catalysis. ${ }^{20} \mathrm{We}$ anticipated observing electronic communication between CDs and rylene chromophores, as PDIs are also known to undergo one-electron reduction, ${ }^{20 a}$ in presence of amine donors and irradiation, while the amino groups on the NCNDs surface have been reported to oxidize relatively easily. ${ }^{14}$

\section{Results and discussion}

\section{Syntheses of reference compounds and rylene monoimide monoanhydrides}

The preparation of symmetric naphthalene and perylene diimides reference compounds was accomplished in a straightforward manner, by taking advantage of literature procedures (Scheme 1). ${ }^{21}$ Specifically, heating a mixture of naphthalene dianhydride and an excess of butylamine, in acetic acid, yielded $N, N^{\prime}$-bis( $n$-butyl)naphthalene-1,4,5,8-tetracarboxylic diimide (NDIRef), after work-up and purification. ${ }^{21 b}$ On the other hand, the reference perylene diimide was prepared by reacting commercial perylene dianhydride with 2,6-diisopropylaniline, in molten imidazole, in order to obtain $N, N^{\prime}$-bis(2,6-diisopropylphenyl)perylene3,4,9,10-tetracarboxylic diimide (PDI-Ref). ${ }^{21 a}$ For the preparation of the unsymmetrical naphthalene and perylene diimides precursors for the imidization reactions with carbon dots, different procedures had to be employed. In the case of naphthalene monoimide monoanhydride (1), the product was obtained, in one step, by refluxing an equimolar solution of $n$-butylamine and naphthalene dianhydride in a phosphate buffered solution. ${ }^{22}$ Although it is possible to prepare unsymmetrical PDIs in one step, ${ }^{23}$ the path to pure and sterically hindered perylene monoimide monoanhydrides requires additional steps. First, the perylene dianhydride (PTCDA) was converted into the tetrabutyl tetraester $(3),{ }^{24}$ which can be relatively easily transformed into
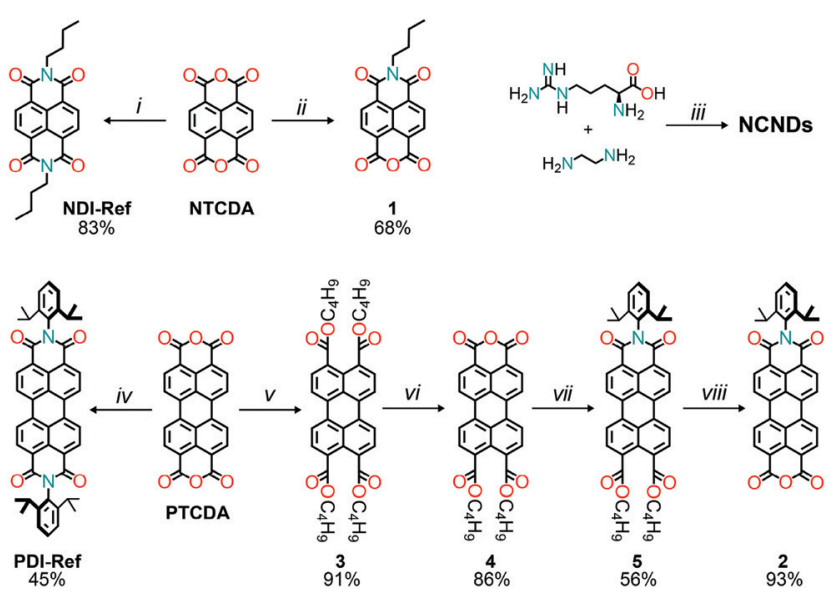

Scheme 1 Reagents and conditions for the preparation of compounds. (i) $n$-Butylamine, $\mathrm{CH}_{3} \mathrm{COOH}, 100{ }^{\circ} \mathrm{C}$, overnight; (ii) $n$-butylamine, $\mathrm{H}_{2} \mathrm{O}$ $\mathrm{pH}=6.4,100{ }^{\circ} \mathrm{C}$, overnight; (iii) $\mathrm{H}_{2} \mathrm{O}, 240{ }^{\circ} \mathrm{C}, \mu \mathrm{W}, 180 \mathrm{~s}$; (iv) 2,6-diisopropylaniline, imidazole, $190{ }^{\circ} \mathrm{C}, \mathrm{N}_{2}, 24 \mathrm{~h}$; (v) $n$-butanol, 1-bromobutane, 1,8-diazabicyclo[5.4.0]undec-7-ene, DMF, $60{ }^{\circ} \mathrm{C}$, overnight; (vi) $p$-toluenesulfonic acid, toluene/hexane (v/v), $100{ }^{\circ} \mathrm{C}, 5 \mathrm{~h}$; (vii) 2,6-diisopropylaniline, imidazole, $130{ }^{\circ} \mathrm{C}, \mathrm{N}_{2}, 5 \mathrm{~h}$; (viii) $\mathrm{H}_{2} \mathrm{SO}_{4}, \mathrm{CH}_{3} \mathrm{COOH}, 118{ }^{\circ} \mathrm{C}, 2 \mathrm{~h}$. 
the monoanhydride diester $(\mathbf{4}),{ }^{25}$ by carefully adjusting the reaction conditions (namely heating a toluene/hexane solvent mixture in a $5: 1 \mathrm{v} / \mathrm{v}$ ratio). The monoanhydride diester was then reacted with 2,6-diisopropylaniline to obtain the monoimide diester (5). ${ }^{26}$ Finally, the monoimide diester was transformed into monoimide monoanhydride (2) by refluxing an acetic acid (with sulfuric acid) solution, ${ }^{27}$ yielding the precursor for the covalent attachment to NCNDs. Meanwhile, amorphous nitrogen-doped carbon dots (NCNDs) were prepared and purified according to our previously reported procedure, ${ }^{28}$ which gives carbon-based nanoparticles with a homogeneous size distribution around $2.5 \mathrm{~nm}$, blue fluorescence (17\% quantum yield) and with an estimated amount of $1350 \mu \mathrm{mol} \mathrm{g}^{-1}$ amino groups on the surface.

\section{Model reaction with 1,8-naphthalic anhydride}

Before proceeding with the preparation of the covalent (nano)hybrids, we investigated the reaction conditions for the imidization of monoimide monoanhydride precursors, which usually require not only high temperatures, but also long reaction times. ${ }^{29}$ We therefore opted for a microwave-assisted coupling reaction to shorten the reaction times. ${ }^{29 a}$ First, we have tested the stability of NCNDs in the reaction conditions required for the imidization reactions. DMF solutions of only NCNDs and triethylamine were heated under microwave irradiation at $140{ }^{\circ} \mathrm{C}$ for 5,15 and 30 minutes, followed by dilution and acquisition of the UV-Vis spectra. Compared to a solution of untreated NCNDs, the absorption profile did not show significant changes (Fig. 2b), which suggests that the NCNDs are thermally stable, even in solutions. Subsequently, we proceeded with performing control experiments using different molar amounts of 1,8-naphthalic anhydride as a model substrate (Fig. 2c). ${ }^{23}$ The UV-Vis absorbance spectra showed an apparently linear dependency on the equivalent of the naphthalene monoanhydride (NMA) precursor used, with the reaction not proceeding after more than 1 equivalent of NMA was added.

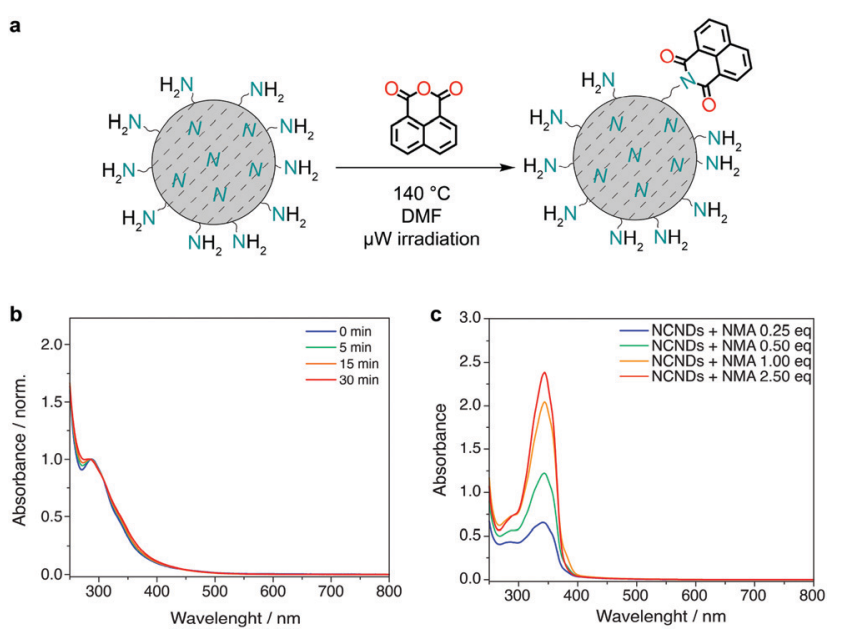

Fig. 2 Probing the imidization reaction. (a) Scheme for the model reaction with 1,8-naphthalic anhydride. (b) UV-vis spectra of CDs under different times of $\mu \mathrm{W}$ irradiation. (c) UV-vis spectra of CDs reacted with different amounts of 1,8-naphthalic anhydride for $30 \mathrm{~min}$.
We have therefore found suitable reaction conditions (DMF, $140{ }^{\circ} \mathrm{C}$ for 30 minutes) for reacting NCNDs with rylene monoimide monoanhydride precursors.

\section{Preparation and characterization of hybrid materials}

The above reaction conditions were employed for coupling NCNDs with naphthalene or perylene monoimide monoanhydrides 1 and $2 .{ }^{30}$ Besides preparing the NCND-NDIs and NCND-PDIs conjugates, we made an effort to prepare a material that contains both NDIs and PDIs, by using 0.25 equivalents of both monomide monoanhydrides precursors, under the same microwave irradiation conditions. ${ }^{31}$ In all three cases, after successful microwave irradiation of the test reactions, the imidization rections were confirmed by recording the UV-Vis spectra (vide infra, Fig. 4), followed by scale-up the reactions. The (nano)hybrids mixtures, after each reaction, were loaded onto a column and purified by size-exclusion chromatography (SEC, DMF as eluent), ${ }^{28 b}$ with the various fractions collected and checked by UV-Vis spectroscopy. Finally, the product fractions were combined, dried under reduced pressure, and collected as powders after lyophilization.

In order to confirm the successful imidization reaction and formation of the hybrid materials, we performed Fouriertransform infrared spectrophotometry (Fig. 3 and ESI, $\dagger$ Fig. S2-S4). The FT-IR spectrum of NCNDs typically shows broad peaks that relate to $\mathrm{O}-\mathrm{H} / \mathrm{N}-\mathrm{H}$ bonding at $3357 \mathrm{~cm}^{-1}$, $\mathrm{C}-\mathrm{H}$ stretching vibrations at 2945 and $2873 \mathrm{~cm}^{-1}, \mathrm{C}=\mathrm{O}$ vibrations at 1766, 1705 and $1654 \mathrm{~cm}^{-1}, \mathrm{C}=\mathrm{N}$ at $1575 \mathrm{~cm}^{-1}, \mathrm{C}-\mathrm{N}$ at 1490 and $1451 \mathrm{~cm}^{-1}, \mathrm{C}-\mathrm{O}$ vibrations at 1383 and $1351 \mathrm{~cm}^{-1}$, and $\mathrm{C}-\mathrm{O}-\mathrm{C}$ vibrations at 1210 and $1111 \mathrm{~cm}^{-1}$. In contrast, for the perylene monoimide monoanhydride 2 we observed distinctive $\mathrm{C}=\mathrm{O}$ stretching vibrations for the anhydride at 1771 and $1734 \mathrm{~cm}^{-1}$ and imide at 1702 and $1662 \mathrm{~cm}^{-1}$, in addition to the aromatic $\mathrm{C}-\mathrm{H}$ stretching at $3035 \mathrm{~cm}^{-1}$, aliphatic $\mathrm{C}-\mathrm{H}$ stretching at 2967 and $2866 \mathrm{~cm}^{-1}$, conjugated $\mathrm{C}=\mathrm{C}$ stretching at $1595 \mathrm{~cm}^{-1}, \mathrm{C}-\mathrm{N}$ stretching at $1365 \mathrm{~cm}^{-1}, \mathrm{C}-\mathrm{O}$ stretching at $1247 \mathrm{~cm}^{-1}$, and $\mathrm{C}-\mathrm{H}$ bending at 811 and $739 \mathrm{~cm}^{-1}$. Importantly, the disappearance of the anhydride $\mathrm{C}=\mathrm{O}$ stretching in the conjugates confirmed the successful imidization reaction. Also, additional features confirmed the presence of both NCNDs and perylene diimide. For example, in the $\mathrm{C}-\mathrm{H}$ stretching characteristic region bands at 2955, 2932 and $2873 \mathrm{~cm}^{-1}$ are discernible, $\mathrm{C}=\mathrm{O}$ stretching modes at 1706 and $1665 \mathrm{~cm}^{-1}$ are more pronounced next to the $\mathrm{C}-\mathrm{N}$ stretching at $1355 \mathrm{~cm}^{-1}$ and the $\mathrm{C}-\mathrm{O}$ stretching at $1251 \mathrm{~cm}^{-1}$, which originates from PDIs.

We further characterized the materials by absorption and fluorescence spectroscopies (Fig. 4 and ESI, $\dagger$ Fig. S5-S8). In DMF, both NDI-Ref and the monoanhydride precursor 1 showed two well-resolved absorption peaks due to $\mathrm{S}_{0} \rightarrow \mathrm{S}_{1}$ transitions, which are characteristic for monomeric NDIs: 360 and $381 \mathrm{~nm}$ for NDI-Ref as well as 356 and $374 \mathrm{~nm}$ for $1 .^{32}$ In the NCND-NDIs conjugate, next to the broad absorption originating from NCNDs, two well-resolved absorption peaks confirmed the successful imidization reaction. In fact, the corresponding maxima are identical to those seen for NDI-Ref. In the case of PDI and its monoimide monoanhydride precursor 2, well-resolved 


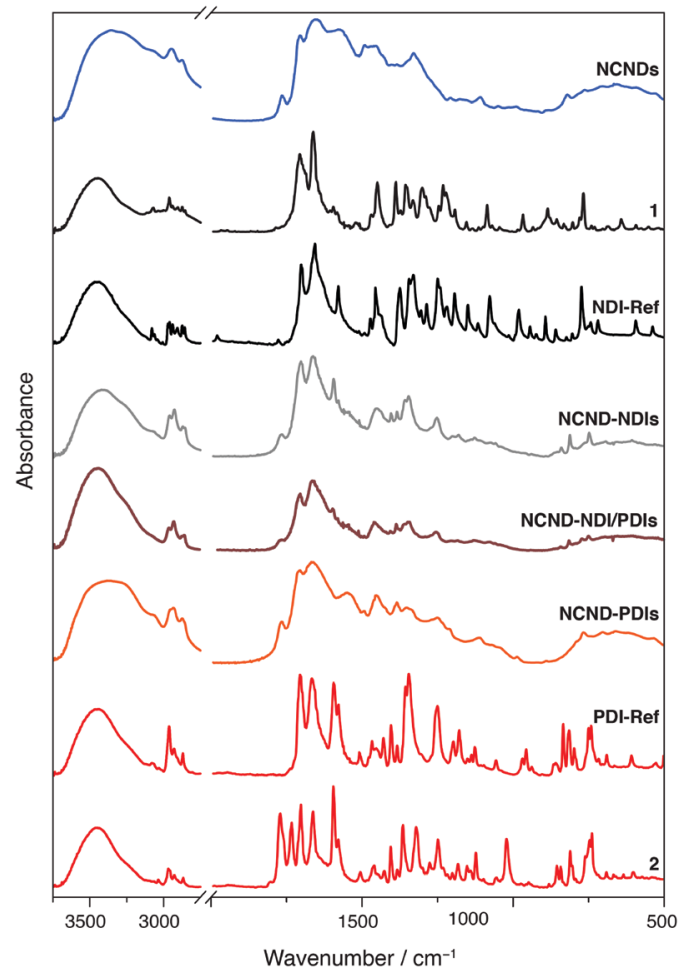

Fig. 3 FT-IR spectra of rylene diimide precursors ( $\mathbf{1}$ and $\mathbf{2}$ ), references (NCNDs, NDI-Ref, PDI-Ref), and hybrid materials (NCND-NDIs, NCNDPDIs, NCND-NDI/PDIs) as KBr pellets.

absorptions were observable. Once again, they originate from the $\mathrm{S}_{0} \rightarrow \mathrm{S}_{1}$ transitions, but they are red-shifted relative to NDI: 492 and $528 \mathrm{~nm}$ for PDI-Ref, as well as 487 and $523 \mathrm{~nm}$ for compound 2. Also in this case, after the imidization reaction, the absorption spectra showed a broad NCND-centered absorption next to well-resolved PDI absorption maxima at 491 and $527 \mathrm{~nm}$. As Fig. 4 shows, the absorption spectra of the NCND-NDI/PDIs conjugate revealed features of all three constituents: broad NCNDcentered absorption in the UV region, NDI-centered maxima at 360 and $381 \mathrm{~nm}$, and PDI-centered maxima at 491 and $527 \mathrm{~nm}$.

As a complement we recorded the fluorescence of all references and conjugates (ESI, $†$ Fig. S8-S12) and obtained evidences of the formation of the conjugates, similar to those concluded from the UV-Vis investigations. Mirror images of the absorptions are the emissions of NCNDs, NDI-Ref, and PDI-Ref in the ranges from 300 to 500,375 to 500 , and 525 to $650 \mathrm{~nm}$, respectively. In terms of fluorescence quantum yields, PDI-Ref is by far the strongest fluorescence with a quantum yield of $93 \%\left(\lambda_{\mathrm{ex}}=480 \mathrm{~nm}\right)$, followed by NCNDs (QY 9.2\%), while NDI-Ref fluorescence is rather weak (QY $<0.1 \%)$. When turning to the NCND-PDIs conjugate, we noted in the 3D heat maps or in the excitation dependent PL spectra (ESI, $\uparrow$ Fig. S8 and S11) PDI-centered fluorescence across the entire excitation wavelength range, that is, from $300 \mathrm{~nm}$ to nearly $550 \mathrm{~nm}$, with very weak residual NCND fluorescent features. The aforementioned leads us to postulate a likely energy transfer scenario. From a closer look at the PDI fluorescence quantum yield of $40 \%\left(\lambda_{\mathrm{ex}}=480 \mathrm{~nm}\right)$, as a qualitative measure for excited state interactions between PDIs and NCNDs, we infer an additional

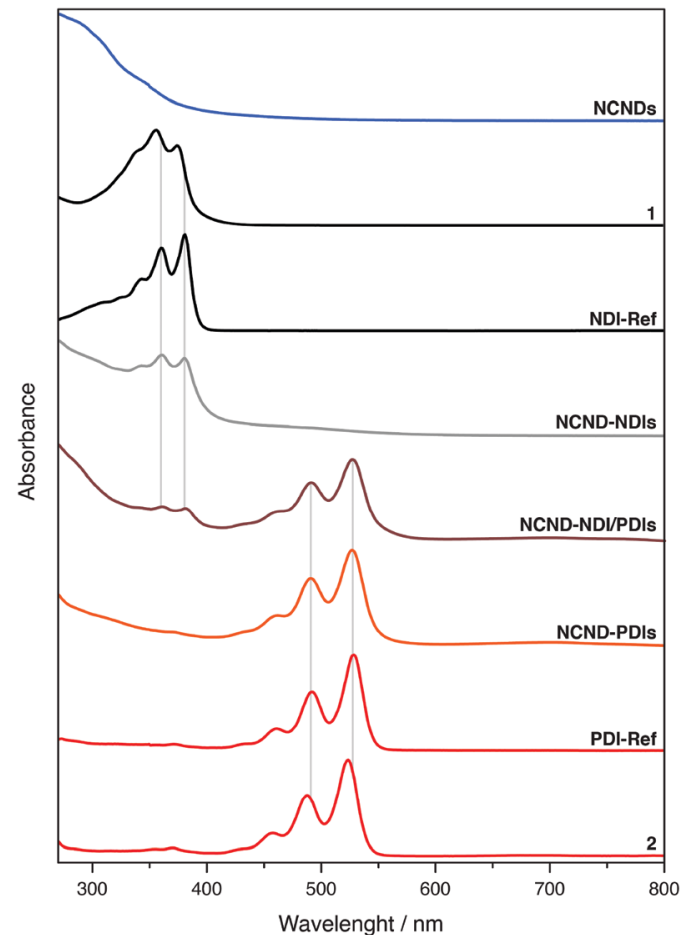

Fig. 4 UV-Vis absorption spectra of rylene diimide precursors (1 and $\mathbf{2}$ ), references (NCNDs, NDI-Ref, PDI-Ref) and hybrid materials (NCND-NDIs, NCND-PDIs, NCND-NDI/PDIs) in DMF, at room temperature. Vertical lines in grey are guides to help the comparison between the naphthalene and perylene diimide-based materials.

deactivation channel once the PDI singlet excited state is formed. The picture is different for the NCND-NDIs conjugate, with the NCND- as well as NDI-centered fluorescence overlapping in the 300 to $500 \mathrm{~nm}$ range and beyond (QY 2.1\%). Besides, a weak excitationdependent emission is observed between $500-600 \mathrm{~nm}$. It is likely to involve from surface trap states originated upon covalent rylene attachment. Interestingly, intense PDI-centered fluorescence obscures the observation of NCND surface trap states in materials containing PDI. We conclude the lack of any NCND-to-NDI energy transfer in NCND-NDIs is due to their nearly isoenergetic excited states. In the NCND-NDI/PDIs conjugate, the PDI-centered fluorescence dominates. As a matter of fact, its quantum yield is $25 \%$ $\left(\lambda_{\mathrm{ex}}=480 \mathrm{~nm}\right)$. From these measurements, we infer that NCNDNDI/PDIs act similar to what we have seen for NCND-PDIs.

As a complement to the steady-state fluorescence measurements we turned to transient absorption measurements (TAS) on the femto-, pico- and nanosecond timescales. We started with the references. In the case of fs-TAS with NCNDs, $387 \mathrm{~nm}$ photoexcitation leads to differential changes that include maxima at 435 and $600 \mathrm{~nm}$ (Fig. S14, ESI $\dagger$ ). A kinetic model, which is based on three species, was used: the initial excited state transformed in 2.4 ps into an intermediate state and subsequently in 370 ps into a very long-lived state (Fig. 5). The third excited state lives longer than the resolution of our experiment. The intermediate state is centered around trap states, which are strongly emissive in NCNDs (vide supra). No signal was, however, observed when exciting NCNDs at $500 \mathrm{~nm}$. 


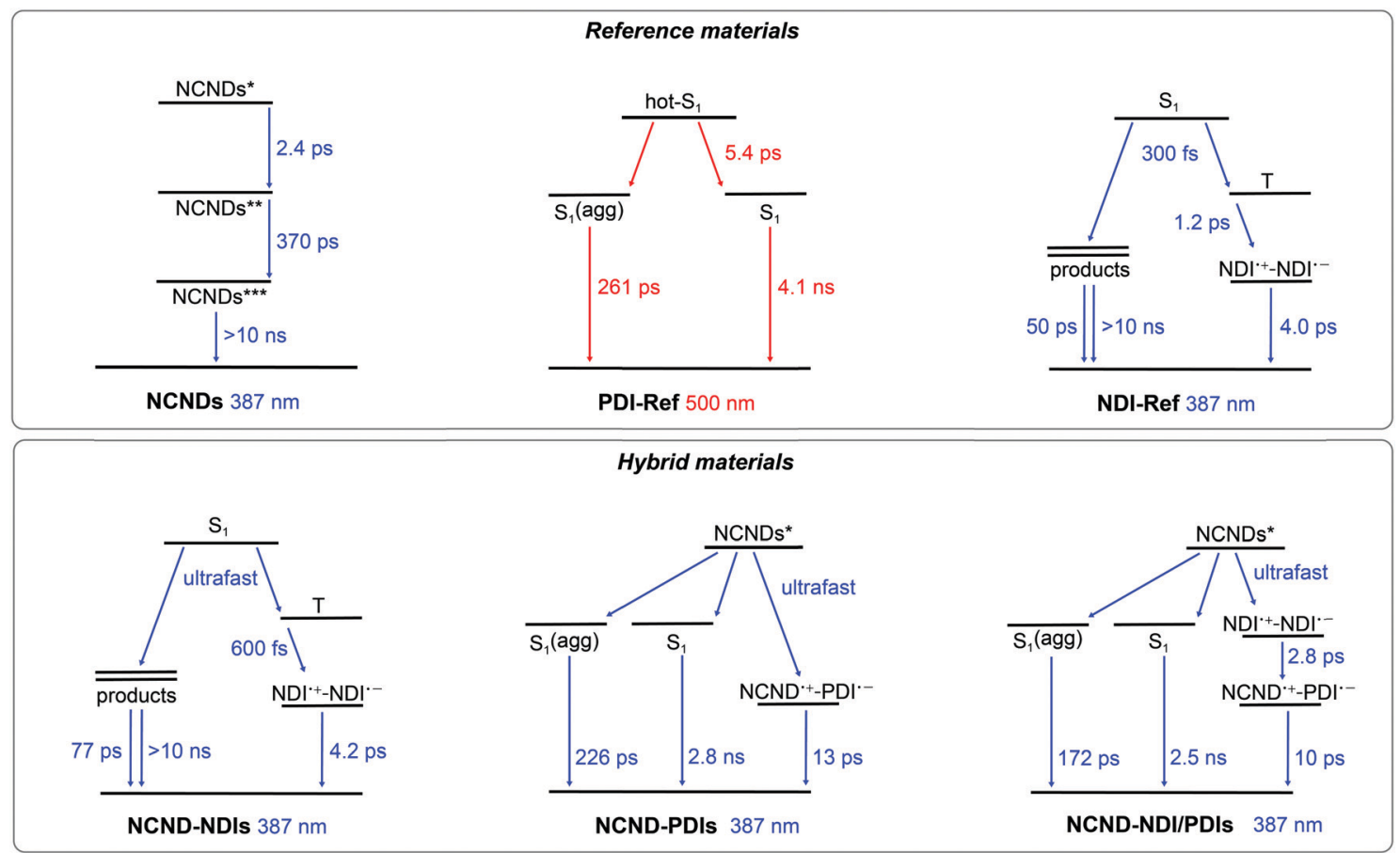

Fig. 5 Kinetic models used to fit the fs-TAS data of reference (NCNDs, PDI-Ref, NDI-Ref) and hybrid materials (NCND-NDIs, NCND-PDIs, NCND-NDI/PDIs).

Turning to PDIs under $500 \mathrm{~nm}$ photoexcitation (Fig. S15, ESI $\dagger$ ), a three species kinetic model was used to fit the experimental data (Fig. 5). The first species with maxima at 695 and $940 \mathrm{~nm}$ as well as minima at 460, 490, 535 and $580 \mathrm{~nm}$ is a vibrationally hot singlet excited state. Notable is the fact that the minima of the first species carry contributions from ground state bleaching at 460, 490 and $535 \mathrm{~nm}$ and stimulated fluorescence at $580 \mathrm{~nm}$. It undergoes vibrational relaxation with a lifetime of 5.4 ps to form, in parallel, the second and the third species. The second species lasts for $261 \mathrm{ps}$ and is ascribed to a vibrationally relaxed singlet excited state of a small PDI-Ref fraction that is aggregated. The third species is the long-lived and bright-fluorescent singlet excited state, with a lifetime of $4.1 \mathrm{~ns}$, by which it decays quantitatively to the ground state. Important is the fact that after vibrational relaxation any appreciable changes are discernable in the differential absorption spectra.

The excited state dynamics of NDI-Ref are quite complex (Fig. S16, ESI $\dagger$ ), in line with literature observations. It has been demonstrated that photoexcitation of NDIs is followed by a very efficient intersystem crossing to the corresponding triplet manifold. ${ }^{33}$ Also, photochemical products and charge separated states evolve from the singlet and triplet excited states, respectively. ${ }^{33}$ In our $387 \mathrm{~nm}$ experiments with NDI-Ref, the singlet excited state with its maxima at 460 and $590 \mathrm{~nm}$ is populated instantaneously, and it intersystem crosses to the triplet excited state within $300 \mathrm{fs}$. The latter is characterized by 479, 590 and $690 \mathrm{~nm}$ maxima and a $1.2 \mathrm{ps}$ lifetime. From this state, the third species evolves, including 480, 608 and $680 \mathrm{~nm}$ characteristics. These signals match the fingerprint absorptions at 474, 608, 680 and $755 \mathrm{~nm}$ obtained upon spectroelectrochemical reduction of NDI-Ref (ESI, $\dagger$ Fig. S13). From this analogy we assign this species to a charge-separated (CS) state. ${ }^{34}$ Finally, CS decays to the ground state via a 4.0 ps lasting charge recombination. Some minor components, all of them with weaker intensity (around 20 times lower), which correspond to photochemical products that originate from the singlet excited state are observed with lifetimes of, for example, 50 ps and $>10 \mathrm{~ns}$.

After gathering information on the references, we focused our attention on NCND-NDIs. When photoexcited at $387 \mathrm{~nm}$, neither the singlet excited state of NDI, nor any NCND-centered excited state were observed (ESI, $\dagger$ Fig. S17). Instead, the first species which was discernable was the triplet excited state of NDI with 470, 590 and $680 \mathrm{~nm}$ maxima as well as a $600 \mathrm{fs}$ lifetime. The latter populates the same CS with maxima at 475, 605 and $680 \mathrm{~nm}$ that was found in the experiments with NDI-Ref. It decays via charge recombination in $4.2 \mathrm{ps}$ to the ground state. Minor components with 77 ps and $>10$ ns lifetimes were also noticed. Overall, the NCND-NDIs dynamics are identical to the NDI-Ref dynamics, and are consistent with the notion of weak excited state interactions between NCNDs and NDIs in NCND-NDIs.

In the case of NCND-PDIs, the differential absorption spectrum, early on, is similar to that of PDI-Ref with maxima at 695 and $930 \mathrm{~nm}$ and minima at 460, 490 and $535 \mathrm{~nm}$. The excited state dynamics of NCND-PDIs upon selective PDI excitation at $500 \mathrm{~nm}$ differ, however, from those described for PDI-Ref. A trend that is evident when comparing the $610 \mathrm{~nm}$ kinetics for PDI-Ref (ESI, $\dagger$ Fig. S15) with those of NCND-PDIs (ESI, $\dagger$ Fig. S18). Global analyses of the data reveal that a four species, rather than a three species, kinetic model is needed to fit the data (ESI, $\dagger$ Fig. S21). Our model includes the decay of the PDI-centered excited states in NCND-PDIs with lifetimes of 2.3 ps for the vibrationally hot singlet excited state, 211 ps for 

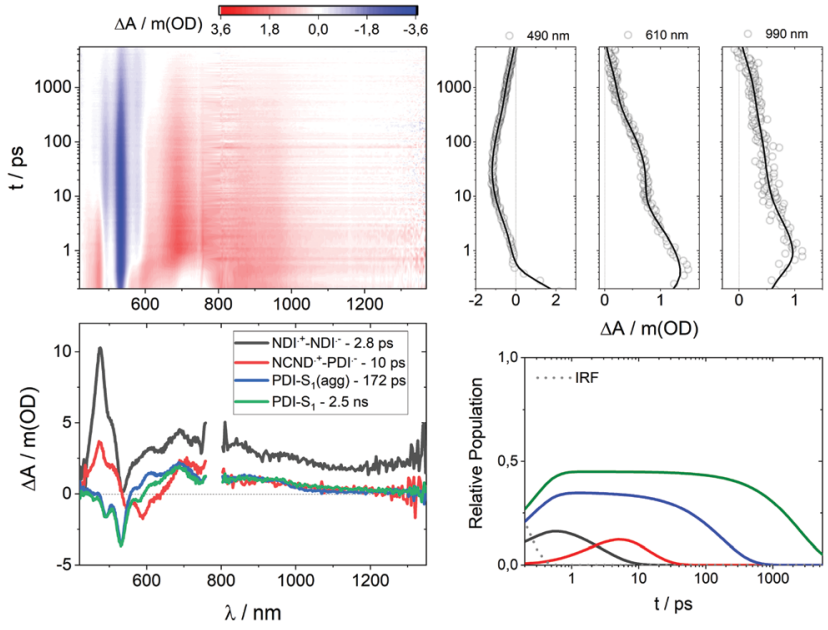

$\Delta \mathrm{A} / \mathrm{m}(\mathrm{OD})$

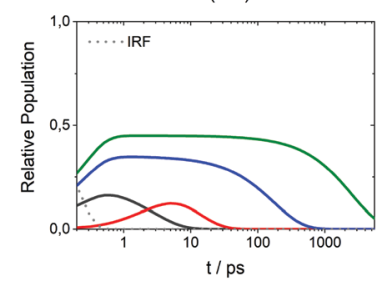

Fig. 6 Top left: Differential absorption 3D map obtained upon fs-TAS of NCND-NDI/PDIs in DMF at room temperature, with $387 \mathrm{~nm}$ excitation. Top right: Time absorption profiles and corresponding fittings at 490, 610, and $990 \mathrm{~nm}$. Bottom left: Species associated differential spectra of the

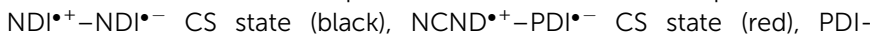
centered $\mathrm{S}_{1}$ (agg) (blue) and PDI-centered $\mathrm{S}_{1}$ (green). Bottom right: Concentration evolution over time.

the vibrationally relaxed singlet excited state in aggregates, and $3.0 \mathrm{~ns}$ for the singlet excited state. The model is also based on an additional excited state, which is populated on the PDI side exclusively from the vibrationally hot singlet excited state and features the fingerprint absorptions of the one electron reduced form of PDI at 690 and $980 \mathrm{~nm}$. These are consistent with those observed for the electrochemically reduced PDI-Ref at 700, 765, 795 and $954 \mathrm{~nm}$ (ESI, $\dagger$ Fig. S13). In essence, this additional excited state is unambiguously assigned to a charge-separated state. CS undergoes charge recombination within 19 ps, by which the ground state is reinstated. We were, however, unable to deconvolute the energy transfer from NCND to PDIs in fs-TAS experiments with NCND-PDIs under $387 \mathrm{~nm}$ excitation (Fig. S19, ESI $\dagger$ ), which assists in selectively photoexciting NCNDs. As a matter of fact, we fit the data using the kinetic model depicted in Fig. 5. It takes an ultrafast energy transfer into account with an upper limit of $300 \mathrm{fs}$. Lifetimes of $226 \mathrm{ps}, 2.8 \mathrm{~ns}$, and $13 \mathrm{ps}$ match the values determined upon $500 \mathrm{~nm}$ excitation. In short, our measurements demonstrate that a CS evolves in NCND-PDIs, either directly after PDI excitation or indirectly after NCND excitation. In the latter case, an energy transfer from NCND to PDI comes first.

Finally, we studied the NCND-NDI/PDIs conjugate, where excitation at $500 \mathrm{~nm}$ initiates the same excited state cascade that was observed for NCND-PDIs upon $500 \mathrm{~nm}$ photoexcitation (please compare the $610 \mathrm{~nm}$ kinetics in Fig S18 and S20, ESI $\dagger$ ). Thus, we applied the same kinetic model, which is based on four species. In NCND-NDI/PDIs, the vibrationally hot singlet excited state decays in $700 \mathrm{fs}$ and feeds the vibrationally relaxed singlet excited state in aggregates, the singlet excited state, and the CS state, whose lifetimes are 218 ps, $3.1 \mathrm{~ns}$ and 16 ps, respectively (ESI, $\dagger$ Fig. S17).

Selective NDI photoexcitation at $387 \mathrm{~nm}$ triggers a complex decay in NCND-NDI/PDIs. Already at very short time delays, the one-electron reduced form of NDI with its $475 \mathrm{~nm}$ characteristic are observed, together with a PDI-centered singlet bleaching at $535 \mathrm{~nm}$ (Fig. 6). Global analyses were performed with a four species kinetic model that is depicted in Fig. 5. We postulate that, right after light absorption, the NDI-centered singlet excited state populates, via intersystem crossing, the $\mathrm{NDI}^{{ }^{+}-\mathrm{NDI}^{\bullet-}}$ CS state, and via energy transfer, the PDI-centered singlet excited states. Notably, the $\mathrm{NDI}^{\bullet+}-\mathrm{NDI}^{{ }^{-}}$CS state, with absorptions at 475,610 and $680 \mathrm{~nm}$ transforms in 2.8 ps to a $\mathrm{NCND}^{{ }^{+}-\mathrm{PDI}^{\bullet-} \mathrm{CS}}$ state, with its fingerprint absorptions at $700 \mathrm{~nm}$ and a shoulder at $990 \mathrm{~nm}$. Per se, this process is remarkable, since the electron and the hole undergo charge shift processes. ${ }^{35}$ Notably, CS in

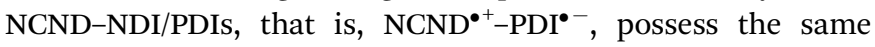
differential absorption spectrum seen for NCND-PDIs (ESI, $\dagger$ Fig. S14). It decays to the ground state via charge recombination in 10 ps. In parallel decay pathways, PDI-centered vibrationally relaxed singlet excited state in aggregates and singlet excited states, with bleaching at 490 and $530 \mathrm{~nm}$, decay with $172 \mathrm{ps}$ and $2.5 \mathrm{~ns}$, respectively.

From our observations, we conclude that in the NCNDNDIs/PDIs, inter-chromophore interactions take place in the excited state, in the form of energy transfer, charge transfer, and charge shift processes.

\section{Conclusion}

In the present work we have synthesized two rylene monoimide monoanhydrides (naphthalene $\mathbf{1}$ and perylene 2) and have performed imidization reactions with the amines present on the surface of amorphous $\mathrm{N}$-doped carbon nanodots. The imidization reaction was first optimized using 1,8-naphthalic anhydride as model compound, in DMF and under microwave irradiation. Imidization reactions with the rylene diimides were confirmed by infrared spectrophotometry and photophysical characterizations. Given the interest that the carbon dots have recently attracted in electron donor-acceptor systems and as scaffolds that support electronic communication between dyes, this work expands the chemical toolbox, in terms of reactions and chromophores employed. In this contribution, we employed chromophores displaying absorption in different regions of the visible spectra, and demonstrated that their excited states are electronically communicating. We envisage the use of CDs other than the ones presently used and different rylene diimides for the preparation of multichromophoric arrays or hybrid polymers with panchromatic absorption.

\section{Conflicts of interest}

There are no conflicts to declare.

\section{Acknowledgements}

This work was supported by the University of Trieste, INSTM, AXA Research Fund, the Italian Ministry of Education MIUR (cofin Prot. 2017PBXPN4), the Spanish Ministry of Economy 
and Competitiveness MINECO (project PID2019-108523RB-I00), and the Maria de Maeztu Units of Excellence Program from the Spanish State Research Agency (MDM-2017-0720). Additional support is acknowledged from the Deutsche Forschungsgemeinschaft (DFG) via SFB 953 "Synthetic Carbon Allotropes" and the Excellence Cluster "Engineering of Advanced Materials". $\mathrm{AC}$ is an ALN member.

\section{Notes and references}

1 (a) E. Schwartz, S. Le Gac, J. J. Cornelissen, R. J. Nolte and A. E. Rowan, Macromolecular multi-chromophoric scaffolding, Chem. Soc. Rev., 2010, 39, 1576-1599; (b) L. Maggini and D. Bonifazi, Hierarchised luminescent organic architectures: design, synthesis, self-assembly, self-organisation and functions, Chem. Soc. Rev., 2012, 41, 211-241; (c) F. Ishiwari, Y. Shoji and T. Fukushima, Supramolecular scaffolds enabling the controlled assembly of functional molecular units, Chem. Sci., 2018, 9, 2028-2041; (d) C. Gong, S. Sun, Y. Zhang, L. Sun, Z. Su, A. Wu and G. Wei, Hierarchical nanomaterials via biomolecular self-assembly and bioinspiration for energy and environmental applications, Nanoscale, 2019, 11, 4147-4182; (e) O. Dumele, J. Chen, J. V. Passarelli and S. I. Stupp, Supramolecular Energy Materials, Adv. Mater., 2020, 32, e1907247.

2 P. Cao, X. Su, X. Pan, Z. Liu, W. Chang and M. Li, Structure, assembly and energy transfer of plant photosystem II supercomplex, Biochim. Biophys. Acta, Bioenerg., 2018, 1859, 633-644.

3 (a) U. Lewandowska, S. Corra, W. Zajaczkowski, N. A. K. Ochs, M. S. Shoshan, J. Tanabe, S. Stappert, C. Li, E. Yashima, W. Pisula, K. Müllen and H. Wennemers, Positional Isomers of Chromophore-Peptide Conjugates Self-Assemble into Different Morphologies, Chem. - Eur. J., 2018, 24, 12623-12629; (b) L. Rocard, D. Wragg, S. A. Jobbins, L. Luciani, J. Wouters, S. Leoni and D. Bonifazi, Templated Chromophore Assembly on Peptide Scaffolds: A Structural Evolution, Chem. - Eur. J., 2018, 24, 16136-16148.

4 (a) Y. N. Teo and E. T. Kool, DNA-multichromophore systems, Chem. Rev., 2012, 112, 4221-4245; (b) P. Ensslen and H. A. Wagenknecht, One-Dimensional Multichromophor Arrays Based on DNA: From Self-Assembly to Light-Harvesting, Acc. Chem. Res., 2015, 48, 2724-2733.

5 (a) H. Q. Peng, Y. Z. Chen, Y. Zhao, Q. Z. Yang, L. Z. Wu, C. H. Tung, L. P. Zhang and Q. X. Tong, Artificial lightharvesting system based on multifunctional surface-crosslinked micelles, Angew. Chem., Int. Ed., 2012, 51, 2088-2092; (b) Z. M. Hudson, D. J. Lunn, M. A. Winnik and I. Manners, Colour-tunable fluorescent multiblock micelles, Nat. Commun., 2014, 5, 3372.

6 (a) G. Bottari, M. A. Herranz, L. Wibmer, M. Volland, L. Rodríguez-Pérez, D. M. Guldi, A. Hirsch, N. Martín, F. D'Souza and T. Torres, Chemical functionalization and characterization of graphene-based materials, Chem. Soc. Rev., 2017, 46, 4464-4500; (b) E. M. Pérez and N. Martín, $\pi-\pi$ interactions in carbon nanostructures, Chem. Soc. Rev., 2015,
44, 6425-6433; (c) L. Đordević, T. Marangoni, F. De Leo, I. Papagiannouli, P. Aloukos, S. Couris, E. Pavoni, F. Monti, N. Armaroli, M. Prato and D. Bonifazi, [60]Fullerene-porphyrin [n]pseudorotaxanes: self-assembly, photophysics and thirdorder NLO response, Phys. Chem. Chem. Phys., 2016, 18, 11858-11868; (d) L. Đordević, T. Marangoni, M. Liu, R. De Zorzi, S. Geremia, A. Minoia, R. Lazzaroni, Y. Ishida and D. Bonifazi, Templating Porphyrin Anisotropy via Magnetically Aligned Carbon Nanotubes, ChemPlusChem, 2019, 84, 1270-1278.

7 (a) S. N. Baker and G. A. Baker, Luminescent carbon nanodots: emergent nanolights, Angew. Chem., Int. Ed., 2010, 49, 6726-6744; (b) F. Arcudi, L. Đordević and M. Prato, Design, Synthesis, and Functionalization Strategies of Tailored Carbon Nanodots, Acc. Chem. Res., 2019, 52, 2070-2079; (c) Y. Xiong, J. Schneider, E. V. Ushakova and A. L. Rogach, Influence of molecular fluorophores on the research field of chemically synthesized carbon dots, Nano Today, 2018, 23, 124-139; (d) Z. Kang and S. T. Lee, Carbon dots: advances in nanocarbon applications, Nanoscale, 2019, 11, 19214-19224; (e) B. Yao, H. Huang, Y. Liu and Z. Kang, Carbon Dots: A Small Conundrum, Trends Chem., 2019, 1, 235-246; ( $f$ ) A. Cadranel, J. T. Margraf, V. Strauss, T. Clark and D. M. Guldi, Carbon Nanodots for ChargeTransfer Processes, Acc. Chem. Res., 2019, 52, 955-963; (g) N. Dhenadhayalan, K. C. Lin and T. A. Saleh, Recent Advances in Functionalized Carbon Dots toward the Design of Efficient Materials for Sensing and Catalysis Applications, Small, 2020, 16, e1905767; (h) Q. Zhao, W. Song, B. Zhao and B. Yang, Spectroscopic studies of the optical properties of carbon dots: recent advances and future prospects, Mater. Chem. Front., 2020, 4, 472-488; (i) Y. Liu, H. Huang, W. Cao, B. Mao, Y. Liu and Z. Kang, Advances in carbon dots: from the perspective of traditional quantum dots, Mater. Chem. Front., 2020, 4, 1586-1613.

8 (a) G. A. M. Hutton, B. C. M. Martindale and E. Reisner, Carbon dots as photosensitisers for solar-driven catalysis, Chem. Soc. Rev., 2017, 46, 6111-6123; (b) C. Hu, M. Li, J. Qiu and Y. P. Sun, Design and fabrication of carbon dots for energy conversion and storage, Chem. Soc. Rev., 2019, 48, 2315-2337; (c) I. Srivastava, J. S. Khamo, S. Pandit, P. Fathi, X. Huang, A. Cao, R. T. Haasch, S. Nie, K. Zhang and D. Pan, Influence of Electron Acceptor and Electron Donor on the Photophysical Properties of Carbon Dots: A Comparative Investigation at the Bulk-State and Single-Particle Level, Adv. Funct. Mater., 2019, 29, 1902466; (d) A. Madonia, M. MartinSabi, A. Sciortino, S. Agnello, M. Cannas, S. Ammar, F. Messina and D. Schaming, Highly Efficient Electron Transfer in a Carbon Dot-Polyoxometalate Nanohybrid, J. Phys. Chem. Lett., 2020, 11, 4379-4384; (e) H. Luo, Q. Guo, P. Á. Szilágyi, A. B. Jorge and M.-M. Titirici, Carbon Dots in Solar-to-Hydrogen Conversion, Trends Chem., 2020, 2, 623-637.

9 (a) A. Cadranel, V. Strauss, J. T. Margraf, K. A. Winterfeld, C. Vogl, L. Đordević, F. Arcudi, H. Hoelzel, N. Jux, M. Prato and D. M. Guldi, Screening Supramolecular Interactions between Carbon Nanodots and Porphyrins, J. Am. Chem. Soc., 2018, 140, 904-907; (b) S. Bettini, S. Sawalha, L. Carbone, G. Giancane, 
M. Prato and L. Valli, Carbon nanodot-based heterostructures for improving the charge separation and the photocurrent generation, Nanoscale, 2019, 11, 7414-7423; (c) L. Đordević, F. Arcudi, A. D’Urso, M. Cacioppo, N. Micali, T. Burgi, R. Purrello and M. Prato, Design principles of chiral carbon nanodots help convey chirality from molecular to nanoscale level, Nat. Commun., 2018, 9, 3442.

10 V. Strauss, J. T. Margraf, K. Dirian, Z. Syrgiannis, M. Prato, C. Wessendorf, A. Hirsch, T. Clark and D. M. Guldi, Carbon Nanodots: Supramolecular Electron Donor-Acceptor Hybrids Featuring Perylenediimides, Angew. Chem., Int. Ed., 2015, 54, 8292-8297.

11 A. Ferrer-Ruiz, T. Scharl, P. Haines, L. Rodríguez-Pérez, A. Cadranel, M. A. Herranz, D. M. Guldi and N. Martín, Exploring Tetrathiafulvalene-Carbon Nanodot Conjugates in Charge Transfer Reactions, Angew. Chem., Int. Ed., 2018, 57, 1001-1005.

12 M. Vázquez-Nakagawa, L. Rodríguez-Pérez, M. A. Herranz and N. Martín, Chirality transfer from graphene quantum dots, Chem. Commun., 2016, 52, 665-668.

13 (a) Z. Ma, Y. L. Zhang, L. Wang, H. Ming, H. Li, X. Zhang, F. Wang, Y. Liu, Z. Kang and S. T. Lee, Bioinspired photoelectric conversion system based on carbon-quantum-dotdoped dye-semiconductor complex, ACS Appl. Mater. Interfaces, 2013, 5, 5080-5084; (b) V. Strauss, J. T. Margraf, T. Clark and D. M. Guldi, A carbon-carbon hybrid - immobilizing carbon nanodots onto carbon nanotubes, Chem. Sci., 2015, 6, 6878-6885; (c) D. H. Hasenohrl, A. Saha, V. Strauss, L. Wibmer, S. Klein, D. M. Guldi and A. Hirsch, Bulbous gold-carbon nanodot hybrid nanoclusters for cancer therapy, J. Mater. Chem. B, 2017, 5, 8591-8599; (d) L. Vallan, R. Canton-Vitoria, H. B. Gobeze, Y. Jang, R. Arenal, A. M. Benito, W. K. Maser, F. D'Souza and N. Tagmatarchis, Interfacing Transition Metal Dichalcogenides with Carbon Nanodots for Managing Photoinduced Energy and Charge-Transfer Processes, J. Am. Chem. Soc., 2018, 140, 13488-13496; (e) Y. Choi, D. Jeon, Y. Choi, J. Ryu and B. S. Kim, Self-Assembled Supramolecular Hybrid of Carbon Nanodots and Polyoxometalates for Visible-Light-Driven Water Oxidation, ACS Appl. Mater. Interfaces, 2018, 10, 13434-13441; $(f)$ H. Luo, S. Dimitrov, M. Daboczi, J.-S. Kim, Q. Guo, Y. Fang, M.-A. Stoeckel, P. Samorì, O. Fenwick, A. B. Jorge Sobrido, X. Wang and M.-M. Titirici, NitrogenDoped Carbon Dots/TiO ${ }_{2}$ Nanoparticle Composites for Photoelectrochemical Water Oxidation, ACS Appl. Nano Mater., 2020, 3, 3371-3381.

14 S. Carrara, F. Arcudi, M. Prato and L. De Cola, Amine-Rich Nitrogen-Doped Carbon Nanodots as a Platform for SelfEnhancing Electrochemiluminescence, Angew. Chem., Int. Ed., 2017, 56, 4757-4761.

15 F. Arcudi, V. Strauss, L. Đordević, A. Cadranel, D. M. Guldi and M. Prato, Porphyrin Antennas on Carbon Nanodots: Excited State Energy and Electron Transduction, Angew. Chem., Int. Ed., 2017, 56, 12097-12101.

16 M. Cacioppo, T. Scharl, L. Dordevic, A. Cadranel, F. Arcudi, D. M. Guldi and M. Prato, Symmetry-Breaking ChargeTransfer Chromophore Interactions Supported by Carbon Nanodots, Angew. Chem., Int. Ed., 2020, 59, 12779-12784.
17 (a) T. Weil, T. Vosch, J. Hofkens, K. Peneva and K. Müllen, The rylene colorant family-tailored nanoemitters for photonics research and applications, Angew. Chem., Int. Ed., 2010, 49, 9068-9093; (b) J. T. Markiewicz and F. Wudl, Perylene, Oligorylenes, and Aza-Analogs, ACS Appl. Mater. Interfaces, 2015, 7, 28063-28085; (c) F. Würthner, C. R. SahaMöller, B. Fimmel, S. Ogi, P. Leowanawat and D. Schmidt, Perylene Bisimide Dye Assemblies as Archetype Functional Supramolecular Materials, Chem. Rev., 2016, 116, 962-1052; (d) A. Nowak-Król and F. Würthner, Progress in the synthesis of perylene bisimide dyes, Org. Chem. Front., 2019, 6, 1272-1318; (e) L. Đordević, D. Milano, N. Demitri and D. Bonifazi, O-Annulation to Polycyclic Aromatic Hydrocarbons: A Tale of Optoelectronic Properties from Five- to SevenMembered Rings, Org. Lett., 2020, 22, 4283-4288.

18 (a) J. D. Yuen and F. Wudl, Strong acceptors in donoracceptor polymers for high performance thin film transistors, Energy Environ. Sci., 2013, 6; (b) J. Feng, W. Jiang and Z. Wang, Synthesis and Application of Rylene Imide Dyes as Organic Semiconducting Materials, Chem. - Asian J., 2018, 13, 20-30; (c) J. Wang and X. Zhan, Rylene Diimide Electron Acceptors for Organic Solar Cells, Trends Chem., 2019, 1, 869-881.

19 (a) T. Weil, T. Vosch, J. Hofkens, K. Peneva and K. Mullen, The rylene colorant family-tailored nanoemitters for photonics research and applications, Angew. Chem., Int. Ed., 2010, 49, 9068-9093; (b) R. K. Dubey, D. Inan, S. Sengupta, E. J. R. Sudholter, F. C. Grozema and W. F. Jager, Tunable and highly efficient light-harvesting antenna systems based on 1,7-perylene-3,4,9,10-tetracarboxylic acid derivatives, Chem. Sci., 2016, 7, 3517-3532.

20 (a) I. Ghosh, T. Ghosh, J. I. Bardagi and B. König, Reduction of aryl halides by consecutive visible light-induced electron transfer processes, Science, 2014, 346, 725-728; (b) M. Marchini, A. Gualandi, L. Mengozzi, P. Franchi, M. Lucarini, P. G. Cozzi, V. Balzani and P. Ceroni, Mechanistic insights into two-photondriven photocatalysis in organic synthesis, Phys. Chem. Chem. Phys., 2018, 20, 8071-8076.

21 (a) C. Ramanan, A. L. Smeigh, J. E. Anthony, T. J. Marks and M. R. Wasielewski, Competition between singlet fission and charge separation in solution-processed blend films of 6,13-bis(triisopropylsilylethynyl)pentacene with stericallyencumbered perylene-3,4:9,10-bis(dicarboximide)s, J. Am. Chem. Soc., 2012, 134, 386-397; (b) Y. Matsunaga, K. Goto, K. Kubono, K. Sako and T. Shinmyozu, Photoinduced color change and photomechanical effect of naphthalene diimides bearing alkylamine moieties in the solid state, Chem. - Eur. J., 2014, 20, 7309-7316.

22 S. K. Nalluri, C. Berdugo, N. Javid, P. W. Frederix and R. V. Ulijn, Biocatalytic self-assembly of supramolecular chargetransfer nanostructures based on n-type semiconductorappended peptides, Angew. Chem., Int. Ed., 2014, 53, 5882-5887.

23 M. J. Robb, B. Newton, B. P. Fors and C. J. Hawker, One-step synthesis of unsymmetrical N-alkyl-N'-aryl perylene diimides, J. Org. Chem., 2014, 79, 6360-6365. 
24 Y. Li, C. Wang, C. Li, S. Di Motta, F. Negri and Z. Wang, Synthesis and properties of ethylene-annulated di(perylene diimides), Org. Lett., 2012, 14, 5278-5281.

25 L. George, Z. Ahmed, H. Lemmetyinen and A. Efimov, Controlled Regioselective Amination of Peryleneimides, Eur. J. Org. Chem., 2015, 584-590.

26 W. E. Benjamin, D. R. Veit, M. J. Perkins, E. Bain, K. Scharnhorst, S. McDowall, D. L. Patrick and J. D. Gilbertson, Sterically Engineered Perylene Dyes for High Efficiency Oriented Fluorophore Luminescent Solar Concentrators, Chem. Mater., 2014, 26, 1291-1293.

27 V. Kunz, V. Stepanenko and F. Würthner, Embedding of a ruthenium(II) water oxidation catalyst into nanofibers via self-assembly, Chem. Commun., 2015, 51, 290-293.

28 (a) F. Arcudi, L. Đordević and M. Prato, Synthesis, Separation, and Characterization of Small and Highly Fluorescent Nitrogen-Doped Carbon NanoDots, Angew. Chem., Int. Ed., 2016, 55, 2107-2112; (b) L. Đordević, F. Arcudi and M. Prato, Preparation, functionalization and characterization of engineered carbon nanodots, Nat. Protoc., 2019, 14, 2931-2953.

29 (a) K. Tambara, N. Ponnuswamy, G. Hennrich and G. D. Pantos, Microwave-assisted synthesis of naphthalenemonoimides and N-desymmetrized naphthalenediimides, J. Org. Chem., 2011, 76, 3338-3347; (b) R. Sekiya, Y. Uemura,
H. Murakami and T. Haino, White-light-emitting edgefunctionalized graphene quantum dots, Angew. Chem., Int. Ed., 2014, 53, 5619-5623.

30 We settled on using 0.25 eq. of compounds 1 or 2 in order to have some residual free amino groups on the carbon nanodots and keep solubility in polar organic solvents.

31 Being a statistical approach, the control of number and distribution of different chromophores on on CDs is beyond the scope of this work.

32 (a) S. V. Bhosale, C. H. Jani and S. J. Langford, Chemistry of naphthalene diimides, Chem. Soc. Rev., 2008, 37, 331-342; (b) S. L. Suraru and F. Würthner, Strategies for the synthesis of functional naphthalene diimides, Angew. Chem., Int. Ed., 2014, 53, 7428-7448.

33 B. M. Aveline, S. Matsugo and R. W. Redmond, Photochemical Mechanisms Responsible for the Versatile Application of Naphthalimides and Naphthaldiimides in Biological Systems, J. Am. Chem. Soc., 1997, 119, 11785-11795.

34 Charge-separated state may be produced by the reaction of a NDI-Ref triplet excited state with a NDI-Ref in its ground state, as in the reference above.

35 Our attempts to fit the data using models, where both CS states are not connected failed. 